\title{
Dyeing Behavior and Fastness Properties of Corn (PLA) Fiber
}

\author{
Nidhi Sisodia ${ }^{1}$, Dr. M.S. Parmar ${ }^{2}$ \\ ${ }^{I}$ (M.Tech Textile Chemistry, Department of Textile Chemistry, UPTTI Kanpur, India) \\ ${ }_{2}^{2}$ (Deputy Director \& Head, Department of Research \& Product Development \& CQE \\ Northern India Textile Research Association Ghaziabad, India)
}

\begin{abstract}
Corn fibre(PLA) were dyed with two disperse dyes. The corn fibres showed better dye uptake at $110^{\circ} \mathrm{C}$.but at this temperature strength of corn fibre is decreased. In this paper Dyeing behavior of Corn fiber (PLA) was investigated. The corn fiber were evaluated for colour strength, tensile strength, elongation and fastness properties like colour fastness to washing, perspiration, hot pressing and light.

Keywords: Colour strength, PLA fiber, tensile strength, elongation and fastness properties
\end{abstract}

\section{Introduction}

Polyester fiber (PET) is a petroleum-based fiber, its life cycle is claimed to cause a global warming. For this reason, a greener polyester fiber has been developed to use for textile production. Poly (lactic acid), PLA, is considered as the eco-polyester fiber. It is derived from renewable materials e.g. corn, sugar and starch. Fermentation of the materials yields lactic acid which is then used for PLA polymerization [1].

An attempt to use PLA as a textile fiber with the aim of replacing PET, fiber with this green polyester fiber. PLA fiber are more hydrophilic than PET, have a lower density, and have excellent crimp and crimp retention. Shrinkage of PLA materials and thermal bonding temperatures are readily controllable. These PLA fiber tend to be stable to ultra-violet light resulting in fabrics that show little fading. They also offer low flammability and smoke generation characteristics [2].

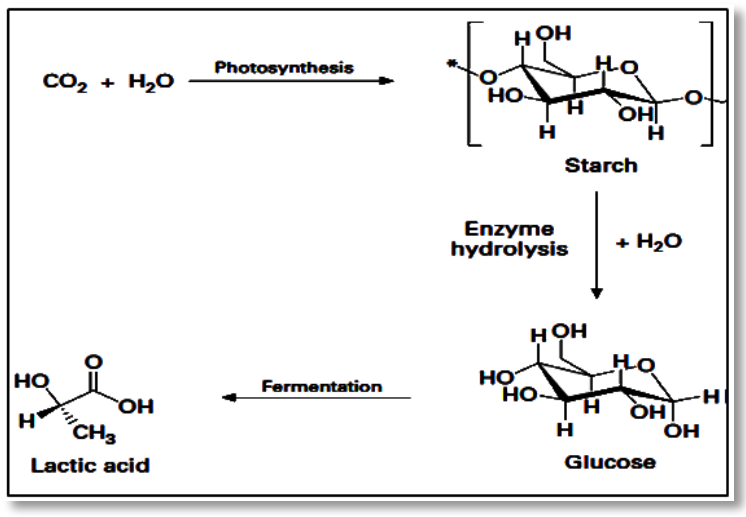

Fig. 1: Production of Lactic Acid From

Renewable Resources

PLA fibers to be seen as a replacement for polyester. Since PLA is a hydrophobic fiber, disperse dyes that have a high affinity for other hydrophobic fibers such as PET are expected to have affinity for PLA. PET is commonly dyed at $130^{\circ} \mathrm{C}$, which is above the melting point of PLA. PLA is generally dyed at $110^{\circ} \mathrm{C}$ and for shorter lengths of time. Excessive heat or extending the dyeing time will cause degradation and loss of tensile strength, molecular weight and elongation at break [3].

\section{Advantages of corn fiber:}

- PLA has over petroleum-based polyesters is that it biodegrades into nontoxic biomasses.

- Bio based polymers such as PLA are capable of biodegrading to carbon dioxide and water. Thus the products will totally biodegrade back to these atmospheric components in 20-30 months in soil and in 30-40 days in standard compost.

- $\quad$ PLA is considered as the eco-polyester fiber. 


\subsection{Material}

\section{Material And Methods}

Corn fibers (PLA), Foron Brill Red SRI, Foron Yellow Brown S2RFLI disperse dyes and Acetic acid ( $\mathrm{pH}$ maintaining), Sodium hydroxide (Alkali Sodium, dithionate (Reducing and wetting agent) Lissapol (Dispersing agent) these material are used for the study. All the chemicals used in the research were supplied from Merck. The fibre properties of PLA and PET fibre are shown in the table 1.

Table 1: Properties of PLA fiber

\begin{tabular}{|l|l|l|}
\hline Properties & PLA & PET \\
\hline Tm (0C) & $130-175$ & $254-260$ \\
\hline Tenacity (g/d) & 6.0 & 6.0 \\
\hline Moisture regain (\%) & $0.4-0.6$ & $0.2-0.4$ \\
\hline Flammability & $\begin{array}{l}\text { Continues to burn for 2 min } \\
\text { after flame removed }\end{array}$ & $\begin{array}{l}\text { Continues to burn for } 6 \mathrm{~min} \\
\text { after flame removed }\end{array}$ \\
\hline Smoke generation & $63 \mathrm{~m}^{2} / \mathrm{kg}$ & $394 \mathrm{~m}^{2} / \mathrm{kg}$ \\
\hline Limiting oxygen index (\%) & 26 & $20-22$ \\
\hline Refractive index & 1.35 & 1.45 \\
\hline
\end{tabular}

\subsection{Dyeing}

Two disperse dye such as Foron Brill Red SRI, Foron Yellow Brown S2RFLI were procured from M/s Clariant (India) Ltd. Fibres were dyed at 2\% shade using IR dyeing machine. The dyeing was carried out at $\mathrm{pH}$ of 5 and $2 \%$ owf depth of the shade was taken. Dyeing process began at $70^{\circ} \mathrm{C}$, dye bath containing dispersing agent, leveling agent. The holding time of the dyeing was 45 minutes. At this time three dyeing studies were carried out by changing temperature from $70^{\circ} \mathrm{C}$ to $110^{\circ} \mathrm{C}$ shown in figure 2,3 and 4 . After dyeing the dye bath was cooled down and reduction clearing was carried out [4].

\subsection{Colour Measurement:}

Colour depth of the dyed fibres were analysed by measuring the K/S values using a Macbeth ColourEye 3100 spectrophotometer. $\mathrm{K} / \mathrm{S}$ is directly proportional to the concentration of colorants in the substrate. Higher the value of K/S, higher will be the concentration of dye in the substrate. The dyed fibres were combed to make them parallel and then attached neatly on the cupboard. The K/S values of the fibres were determined through Kubelka - Munk equation as given below:

$\mathbf{K} / \mathrm{S}=(\mathbf{1 - R})^{2} / 2 \mathbf{R}$

Where,

$\mathbf{R}$ is the reflectance at complete opacity $\mathbf{K}$ is the absorption coefficient

$\mathbf{S}$ is the scattering coefficient

Dyed fibres were simultaneously evaluated in terms

CIELAB colour space $\left(L, a^{*}, b^{*}\right)$ values. In general, the higher the $K / S$ value, the higher the depth of the colour on the fibre of $\mathrm{L}$ correspondence to the brightness $(100=$ white, $0=$ black $)$, $\mathrm{a}^{*}$ to the red - green coordinates $(+\mathrm{ve}=$ yellow,-ve $=$ green $)$ and $\mathrm{b}^{*}$ to the yellow-blue coordinates $(+\mathrm{ve}=\mathrm{yellow},-\mathrm{ve}=$ blue $)$.as $\mathrm{a}$ whole, a combination of all parameters enables one to understand the tonal variations. 


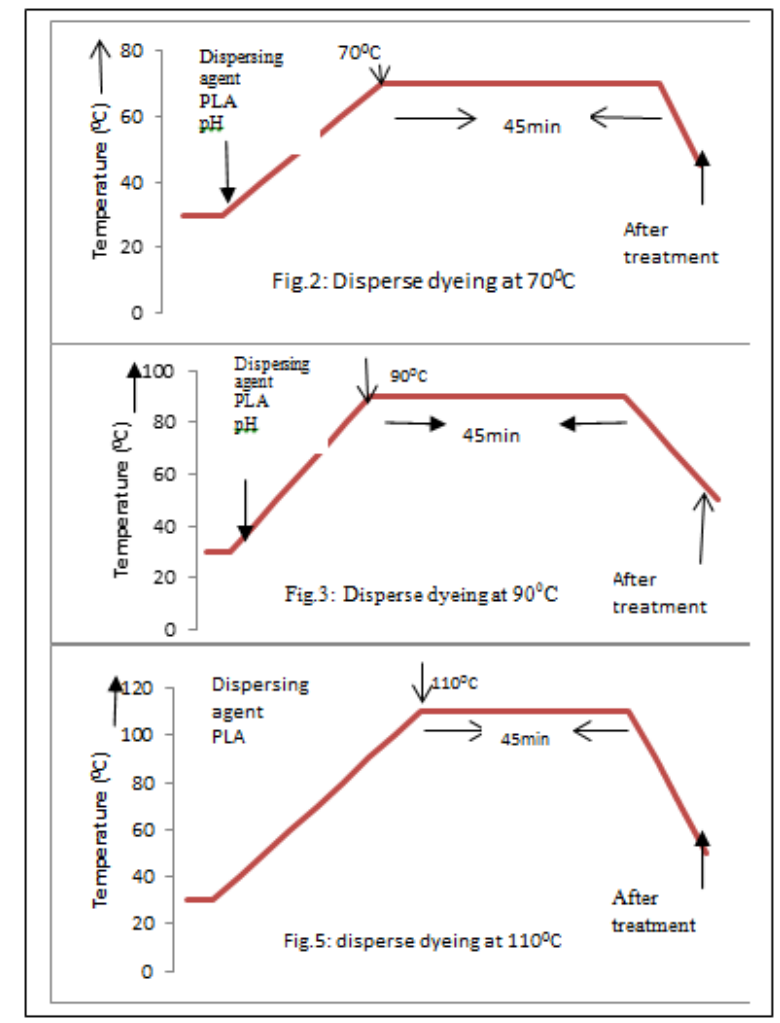

\subsection{Colour fastness properties}

For assessment of quality of dyed fibres samples, colour fastness to washing, light, and perspiration and hot pressing properties were evaluated using ISO $105 \mathrm{C} \mathrm{10A(1),} \mathrm{ISO} 105 \mathrm{~B} 02$, ISO 105 E04 standard test methods respectively. Change in colour and staining on adjacent fibre of the dyed fibre were assessed by giving rating of 1 (poor) to 5(excellent) by comparing with grey scale in the case of colour fastness to washing and perspiration. The colour fastness to light was assessed by comparing the exposed fibres and blue wool standard nos 1 to 8 . The Following tests were carried out as per the standard mentioned in table 2:

Table 2: Standard for Tests Methods

\begin{tabular}{|l|l|}
\hline Test name & Standard \\
\hline Colour fastness to light & IS 2456:1985 \\
\hline Colour fastness to Perspiration & ISO: $105 \mathrm{E}-04$ \\
\hline Colour fastness to washing & ISO: $105-\mathrm{C} 10(3)$ \\
\hline Colour fastness to Hot Pressing & IS-689:1988 \\
\hline Single fiber length & ASTM D1557-07 \\
\hline Tensile strength & ASTM D 3822-07 \\
\hline
\end{tabular}

\subsection{Effect of temperature}

\section{Result and Discussion}

The colour strength of dyed fibres increases with an increase the dyeing temperature. But tensile strength decreased at the temperature raised up to $110^{\circ} \mathrm{C}$. The effect of dyeing temperature on colour strength is shown in table 3 and figure 6.

The dye uptake by the fibres maximum at $110^{\circ} \mathrm{C}$ temperature, but at this temperature dyed fiber is highly rigid in nature. 
Table. 3: K/S Value of Corn Fibre

\begin{tabular}{|l|l|l|l|l|l|}
\hline $\begin{array}{l}\text { Temperature } \\
\left({ }^{0} \mathbf{C}\right)\end{array}$ & Dyes Name & K/S & $\mathbf{L}^{*}$ & $\mathbf{a}^{*}$ & $\mathbf{b}^{*}$ \\
\hline \multirow{3}{*}{$\mathbf{7 0}$} & $\begin{array}{l}\text { Foron yellow brown } \\
\text { S2RFLI }\end{array}$ & 0.77 & 34.720 & 9.852 & 26.243 \\
\cline { 2 - 6 } & Foron brill Red SRI & .38 & 21.671 & 14.866 & 9.373 \\
\hline \multirow{2}{*0}{} & $\begin{array}{l}\text { Foron yellow brown } \\
\text { S2RFLI }\end{array}$ & 11.03 & 57.800 & 28.119 & 60.924 \\
\cline { 2 - 6 } & Foron brill Red SRI & 2.35 & 31.546 & 32.420 & 20.971 \\
\hline \multirow{2}{*}{$\mathbf{1 1 0}$} & $\begin{array}{l}\text { Foron yellow brown } \\
\text { S2RFLI }\end{array}$ & 20.61 & 58.208 & 32.297 & 64.024 \\
\cline { 2 - 6 } & Foron brill Red SRI & 27.29 & 38.843 & 47.777 & 30.323 \\
\hline
\end{tabular}

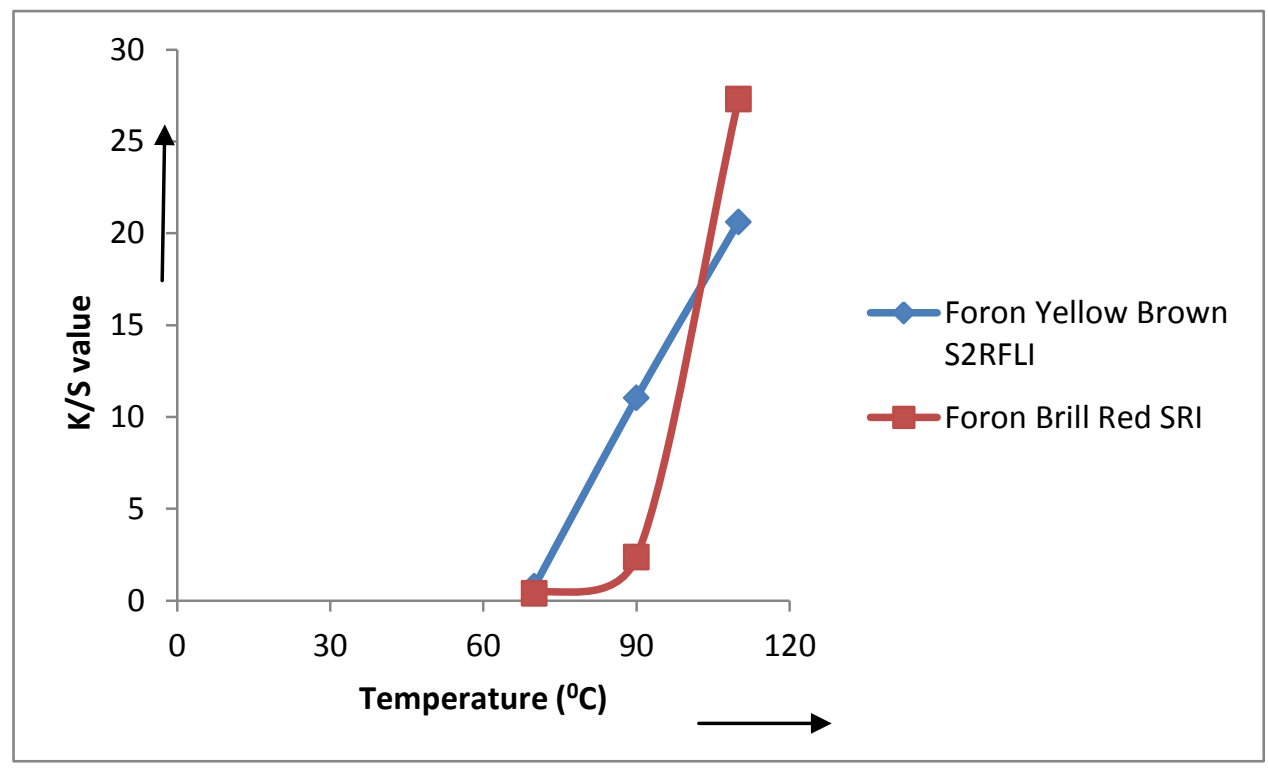

Fig.6: K/S value vs temperature

\subsection{Colour fastness properties}

The results of colour fastness to light, washing, perspiration and hot pressing are reported Table 4, 5, 6 and 7 .

Table 4: Colour Fastness to Light

\begin{tabular}{|l|l|l|}
\hline $\begin{array}{l}\text { Temperature } \\
{ }^{\mathbf{0}} \mathbf{C}\end{array}$ & Dye class & $\begin{array}{l}\text { Rating for change } \\
\text { in colour }\end{array}$ \\
\hline $70^{\circ} \mathrm{C}$ & Foron brill Red SRI & 4 \\
\cline { 2 - 3 } & Foron yellow brownS2RFLI & $3 / 4$ \\
\hline $90^{\circ} \mathrm{C}$ & Foron brill Red SRI & $4-5$ \\
\cline { 2 - 3 } & Foron yellow brownS2RFLI & 5 \\
\hline \multirow{2}{*}{$110^{\circ} \mathrm{C}$} & Foron brill Red SRI & $4-5$ \\
\cline { 2 - 3 } & $\begin{array}{l}\text { Foron yellow brown } \\
\text { S2RFLI }\end{array}$ & 5 \\
\hline
\end{tabular}


Table 5: colour fastness to washing

\begin{tabular}{|c|c|c|c|c|c|c|c|c|c|}
\hline \multirow{2}{*}{$\begin{array}{l}\text { Temp } \\
(0 \mathrm{C})\end{array}$} & \multirow{2}{*}{$\begin{array}{l}\text { Dye class } \\
\text { Acid dye }\end{array}$} & \multirow{2}{*}{$\begin{array}{l}\text { Change } \\
\text { in } \\
\text { colour }\end{array}$} & \multirow{2}{*}{$\begin{array}{l}\text { Staining } \\
\text { on white } \\
\text { cotton }\end{array}$} & \multicolumn{6}{|c|}{ Staining on multi fiber } \\
\hline & & & & wool & Acrylic & Polyester & nylon & cotton & Acetate \\
\hline \multirow[t]{2}{*}{$7^{\circ} \mathrm{c}$} & $\begin{array}{c}\text { Foron brill } \\
\text { Red SRI }\end{array}$ & $4-5$ & 5 & 5 & 5 & $4-5$ & $4-5$ & 5 & 5 \\
\hline & $\begin{array}{c}\text { Foron } \\
\text { yellow } \\
\text { brown } \\
\text { S2RFLI }\end{array}$ & $4-5$ & $4-5$ & $4-5$ & $4-5$ & $4-5$ & $4-5$ & $4-5$ & $4-5$ \\
\hline \multirow[t]{2}{*}{$90^{0} \mathrm{c}$} & $\begin{array}{c}\text { Foron brill } \\
\text { Red SRI }\end{array}$ & $4-5$ & $4-5$ & $4-5$ & $4-5$ & $4-5$ & $4-5$ & $4-5$ & $4-5$ \\
\hline & $\begin{array}{l}\text { Foron } \\
\text { yellow } \\
\text { brown } \\
\text { S2RFLI }\end{array}$ & $4-5$ & $4-5$ & $4-5$ & $4-5$ & $4-5$ & 4 & $4-5$ & $4-5$ \\
\hline \multirow[t]{2}{*}{$110^{\circ} \mathrm{c}$} & $\begin{array}{l}\text { Foron brill } \\
\text { Red SRI }\end{array}$ & 4 & $4-5$ & $4-5$ & $4-5$ & 4 & $3-4$ & $4-5$ & 4 \\
\hline & $\begin{array}{l}\text { Foron } \\
\text { yellow } \\
\text { brown } \\
\text { S2RFLI }\end{array}$ & 3 & $4-5$ & 4 & $4-5$ & $3-4$ & $4-5$ & $4-5$ & 4 \\
\hline
\end{tabular}

Table.6: Colour fastness to perspiration $\left(90^{\circ} \mathrm{C}\right)$

\begin{tabular}{|c|c|c|c|c|c|c|c|c|}
\hline 6 & \multicolumn{8}{|c|}{ Alkaline perspiration } \\
\hline \multirow{2}{*}{$\begin{array}{l}\text { Dye class } \\
\text { Disperse dye }\end{array}$} & \multirow{2}{*}{$\begin{array}{l}\text { Change in } \\
\text { colour }\end{array}$} & \multirow{2}{*}{$\begin{array}{l}\text { Staining on } \\
\text { white cotton }\end{array}$} & \multicolumn{6}{|c|}{ Staining on multi fiber } \\
\hline & & & Wool & Acrylic & Polyester & Nylon & Cotton & Acetate \\
\hline $\begin{array}{ll}\text { Foron } & \text { Brill } \\
\text { Red SRI } & \end{array}$ & $4-5$ & $4-5$ & $4-5$ & $4-5$ & $4-5$ & $4-5$ & $4-5$ & $4-5$ \\
\hline $\begin{array}{l}\text { Foron Yellow } \\
\text { Brown } \\
\text { S2RFLI }\end{array}$ & $4-5$ & $4-5$ & $4-5$ & $4-5$ & $4-5$ & $4-5$ & $4-5$ & $4-5$ \\
\hline \multicolumn{9}{|c|}{ Acidic perspiration } \\
\hline $\begin{array}{ll}\text { Foron } & \text { Brill } \\
\text { Red SRI } & \\
\end{array}$ & $4-5$ & $4-5$ & $4-5$ & $4-5$ & $4-5$ & $4-5$ & $4-5$ & $4-5$ \\
\hline
\end{tabular}

Table 7: Colorfastness to Hot Pressing $\left(90^{\circ} \mathrm{C}\right)$

\begin{tabular}{|l|l|l|}
\hline Dye class & Change in colour & $\begin{array}{l}\text { Staining on white cotton } \\
\text { cloth }\end{array}$ \\
\hline Foron Brill Red SRI & $4-5$ & $4-5$ \\
\hline Foron Yellow Brown S2RFLI & $4-5$ & $4-5$ \\
\hline
\end{tabular}

\subsection{Single fibre length and tenacity}

From the table 8 and 9 indicate that after dyeing single fibre length of the corn fibre decreased. Tenacity and elongation of dyed fibres decreased as well as temperature increased. 
Table 8: Single fibre length

\begin{tabular}{|c|c|c|}
\hline S.No. & (Before $\quad$ Dyeing) $(\mathrm{mm})$ & $\begin{array}{c}\text { (After Dyeing) } \\
(\mathbf{m m})\end{array}$ \\
\hline 1. & 34 & 37 \\
\hline 2. & 38 & 27 \\
\hline 3. & 39 & 26 \\
\hline 4. & 40 & 36 \\
\hline 5. & 38 & 22 \\
\hline 6. & 43 & 38 \\
\hline 7. & 40 & 25 \\
\hline 8. & 25 & 23 \\
\hline 9. & 42 & 36 \\
\hline 10. & 39 & 36 \\
\hline Mean & 37.8 & 30.6 \\
\hline
\end{tabular}

Table 9: Tensile strength of dyed and undyed Corn fiber

\begin{tabular}{|l|c|c|c|}
\hline \multicolumn{1}{|c|}{ Temperature } & Undyed fiber & $\mathbf{9 0}^{\mathbf{0}} \mathbf{c}$ & $\mathbf{1 1 0}^{\mathbf{0}} \mathbf{c}$ \\
\hline Fiber denier & 1.61 & 1.37 & 1.60 \\
\hline CV\% & 18.11 & 15.47 & 19.22 \\
\hline Tenacity(grm/denier) & 3.44 & 3.30 & .97 \\
\hline CV\% & 20.00 & 27.00 & 16.81 \\
\hline Elongation at break \% & 48.42 & 33.96 & 11.84 \\
\hline CV\% & 34.00 & 32.12 & 34.23 \\
\hline $\begin{array}{l}\text { Single Fiber length in } \\
\text { mm }\end{array}$ & 37.8 & 34.2 & 30.6 \\
\hline
\end{tabular}

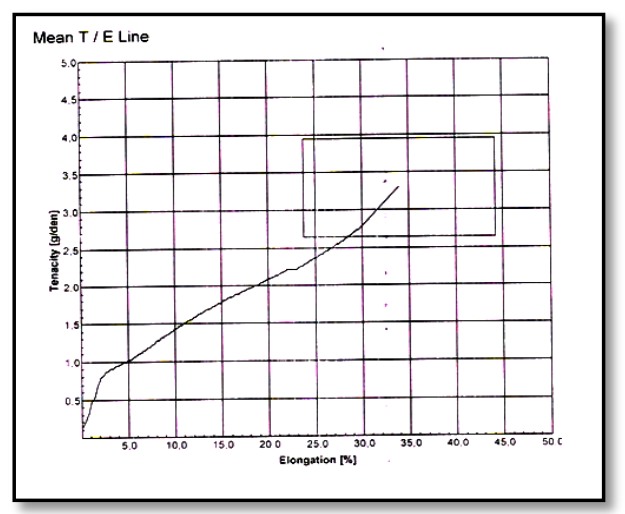

Fig. 8: Mean Tenacity vs E Line Graph of Undyed Corn Fiber

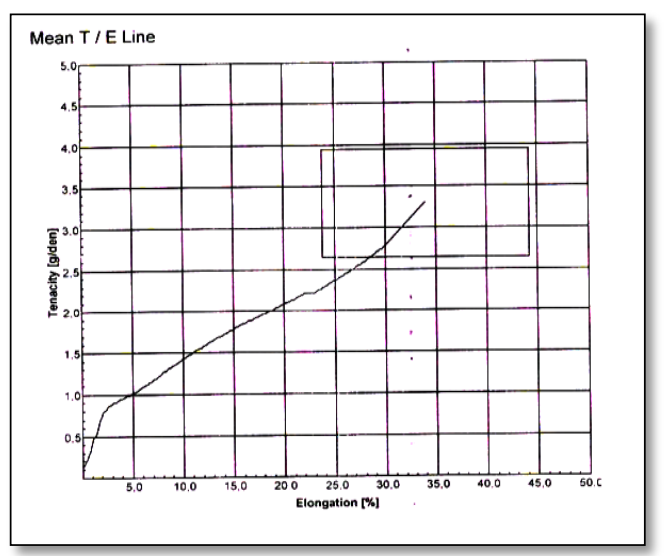

Fig. 9: Mean Tenacity vs E Line Graph of Dyed Corn Fiber at $90^{\circ} \mathrm{C}$ 


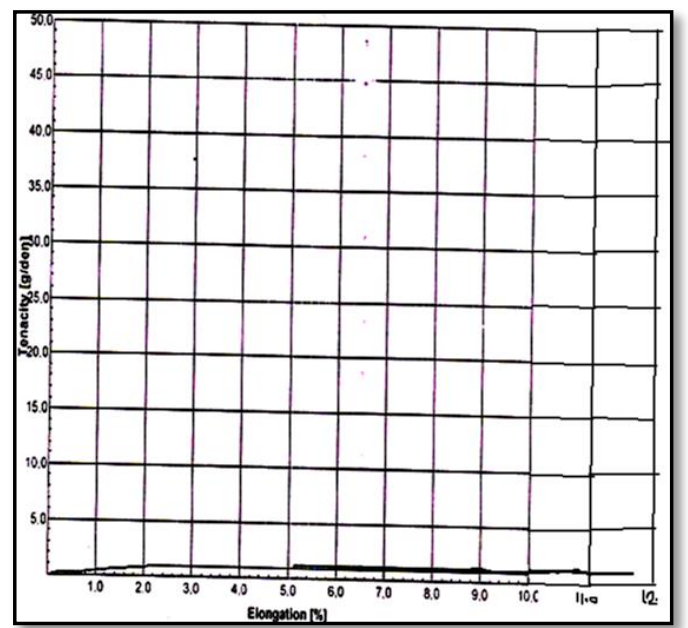

Fig.10: Mean Tenacity vs E Line Graph of Dyed Corn Fiber at $110^{\circ} \mathrm{C}$

\section{Conclusion}

Dyeing behavior of corn (PLA) fibre is showed that at higher temperature the colour strength of Corn fiber was higher as compared to other lower temperature but tenacity decreased at higher temperature due to the structure degradation. Effect of dyeing on fibre properties also studied. It is clear that the tenacity (3.44) and elongation at break (48.42) of undyed fiber was higher as compared to dyed corn fiber $(3.30,33.96)$. As the temperature increased the value of tenacity (.97) as well as elongation at break (11.84) decreased.

\section{Refrences}

[1]. Vorabodee Sriumaoum, Jantip Suesat and Potjanart Suwanruji "Dyeing and Spectroscopic Properties of Natural Dyes on Poly(Lactic Acid) and Poly(Ethylene Terephthalate) Fabrics" International Journal of Bioscience, Biochemistry and Bioinformatics, Vol. 2, No. 3, May 2012.

[2]. Crystallization behavior of poly(lactic acid)/elastomer blends Mujtahid Kaavessina \& Ilias Ali \& Rabeh H. Elleithy \& S. M. A1Zahrani, Springer Science+Business Media B.V. 2012.

[3]. V. S. Giita Silverajah, Nor Azowa Ibrahim and Chieng Buong Woei, A Comparative Study on the Mechanical, Thermal and Morphological Characterization of Poly(lactic acid)/Epoxidized Palm Oil Blend,international journal of molecular science .2012; 13(5);5878-5898

[4]. Sriumaoum, Jantip Suesat, and Potjanart Suwanruji "Dyeing and Spectroscopic Properties of Natural Dyes onPoly (Lactic Acid) and Poly (Ethylene Terephthalate) Fabrics", International Journal of Bioscience, Biochemistry and Bioinformatics, May 2012, Vol. 2, No. 3. 